\title{
ESTUDOS DE CASO EM QUÍMICA
}

Luciana Passos Sá, Cristiane Andretta Francisco e Salete Linhares Queiroz*

Instituto de Química de São Carlos, Universidade de São Paulo, CP 780, 13560-970 São Carlos - SP, Brasil

Recebido em 10/5/06; aceito em 17/7/06; publicado na web em 26/3/07

\begin{abstract}
CASE STUDIES IN CHEMISTRY. The case-study method of instruction is increasing in popularity and instructors of various scientific disciplines are adopting this method for their courses. Its effectiveness suggests that there is a need for such resources to be used in chemistry education. In this paper we describe this method in detail and present our use of cases in a scientific communication course offered to undergraduate chemistry students at the University of São Paulo. The description of the method and the example of its use may be helpful for faculty members who wish to explore new ways to engage students more deeply in their learning and to reinvigorate their own teachig practice.
\end{abstract}

Keywords: undergraduate education; case studies; chemistry.

\section{INTRODUÇÃO}

Nos últimos anos, a preocupação com a adoção de metodologias de ensino que privilegiem o papel do aluno de graduação no processo de aprendizagem vem ganhando destaque e orientando a construção e a concretização de propostas curriculares no mundo inteiro ${ }^{1-3}$. No Brasil, as Diretrizes Curriculares Nacionais Para os Cursos de Química ${ }^{4}$ apontam nesta direção quando afirmam que "os currículos vigentes estão transbordando de conteúdos informativos em flagrante prejuízo aos formativos, fazendo com que o estudante saia do curso de graduação com "conhecimentos" já desatualizados e não suficientes para uma ação interativa e responsável na sociedade, seja como profissional, seja como cidadão" e sugerem que o ensino deve "enfatizar questões como globalização, ética, treinamento em equipe interdisciplinar, necessidade de atualização e ampliação constantes dos conhecimentos, incluindo aspectos regionais".

Neste trabalho descrevemos algumas características e aplicações do método de Estudo de Caso no ensino superior de ciências, em especial no ensino superior de química. Pesquisas na área de educação em ciências mostram sua potencialidade na promoção de um ensino que vise o desenvolvimento de conteúdos não somente informativos, mas também formativos nos cursos de graduaçãa $0^{5-7}$. Considerando que o referido método não tem sido empregado com frequiência no ensino superior de química no Brasil, relatamos também uma experiência realizada no Instituto de Química de São Carlos sobre sua aplicação na disciplina Comunicação e Expressão em Linguagem Científica II ${ }^{8}$.

\section{SOBRE AS ORIGENS DO MÉTODO DE ESTUDO DE CASO E SUA INTRODUÇÃO NO ENSINO SUPERIOR DE CIÊNCIAS}

O método de Estudo de Caso é uma variante do método Aprendizagem Baseada em Problemas (ABP), também conhecido como "Problem Based Learning (PBL)". O ABP teve origem na Escola de Medicina da Universidade de McMaster, Ontário, há aproximadamente $30 \operatorname{anos}^{9}$ e por muito tempo ficou restrito à formação de profissionais da área médica. Trata-se de uma metodologia desenvolvida com o intuito de possibilitar aos alunos o contato com pro-

*e-mail: salete@iqsc.usp.br blemas reais, antes de alcançarem os semestres finais do curso. $\mathrm{O}$ método logo se difundiu pelas faculdades de medicina de diversos países e depois por outros cursos de graduação e pós-graduação ${ }^{10}$. Como muitas variantes do ABP, o Estudo de Caso é um método que oferece aos estudantes a oportunidade de direcionar sua própria aprendizagem, enquanto exploram a ciência envolvida em situações relativamente complexas. Enquanto o objetivo do modelo original do ABP é, principalmente, a aprendizagem do assunto científico, os casos são mais comumente usados para ensinar habilidades para tomada de decisão a profissionais.

Tão antigo quanto contar histórias, o uso de casos é a instrução pelo uso de narrativas sobre indivíduos enfrentando decisões ou dilemas. Na aplicação deste método o aluno é incentivado a se familiarizar com personagens e circunstâncias mencionados em um caso, de modo a compreender os fatos, valores e contextos nele presentes com o intuito de solucioná-lo. Cursos tais como medicina, direito, psicologia e administração têm utilizado o método com o objetivo de despertar a atenção do estudante e aproximá-lo da realidade prática de sua área. Neste contexto, o papel principal do professor consiste em ajudar o estudante a trabalhar com os fatos e análise de um problema e a considerar, então, as possíveis soluções e consequiências de suas ações ${ }^{11}$.

Embora não tão utilizados em cursos de ciências no ensino superior, principalmente se comparado aos cursos anteriormente mencionados, os casos têm se tornado freqüentes também nesta área ${ }^{12,13}$. Segundo relatos presentes na literatura ${ }^{14}$, J. Conant, da Universidade de Harvard, foi o primeiro educador em ciências a organizar uma disciplina baseada em Estudos de $\operatorname{Casos}^{15}$. Desde então, professores de química ${ }^{16-19}$, física ${ }^{20}$ e biologia ${ }^{11,21,22}$ têm adotado o método.

No que diz respeito à popularização do método de Estudo de Caso no ensino de ciências, é importante mencionar a publicação do artigo intitulado "Case Studies in Science - A Novel Method of Science Education"14. Este veio a ser o primeiro de uma série de artigos publicados no Journal of College Science Teaching, conhecida revista da área de educação em ciências, sobre o uso de casos no ensino de ciências e deu origem à seção denominada The Case Study, que perdura até os dias atuais.

Nos artigos publicados na seção The Case Study, relacionados ao ensino de química, observamos que a resolução dos casos exige, principalmente, conhecimentos vinculados às disciplinas de química geral e bioquímica ${ }^{13,18}$. Porém, somente estes conhecimentos não 
são suficientes para tanto, fazendo-se necessário que a eles sejam acrescentados também conhecimentos adquiridos em outras disciplinas. Podem ser citados como exemplo destes Estudos de Casos os trabalhos de Cornely ${ }^{13}$ e de Karukstis ${ }^{23}$.

O trabalho de Cornely ${ }^{13}$, intitulado "Journal Articles as Case Studies - The New England Journal of Medicine on Lactose Intolerance", trata do uso do método de Estudo de Caso em uma disciplina introdutória de bioquímica: os estudantes recebem um artigo científico publicado no periódico The New England Journal of Medicine e uma série de questões relacionadas ao assunto, que devem ser discutidas em grupo. O professor atua como mediador durante a discussão. Tendo em vista o caráter próprio do artigo científico que relata resultados originais de pesquisa, na resolução deste tipo de caso os estudantes praticam suas habilidades analíticas ao interpretarem gráficos e tabelas e ao criticarem o planejamento de experimentos.

No trabalho de Karukstis ${ }^{23}$, intitulado "Using Case Studies to Introduce Environmental and Economic Considerations", o método de Estudo de Caso é empregado em disciplina de química geral, com intuito de: melhorar a compreensão dos estudantes sobre as relações existentes entre ciência, tecnologia e sociedade; colocar os estudantes em uma posição central no processo educacional; desenvolver habilidades de pensamento crítico de ordem superior dos estudantes, que incluem a identificação de questões chaves e de informações relevantes para a resolução dos casos; melhorar as habilidades de comunicação dos estudantes e favorecer a troca de conhecimentos entre eles. Para atingir tais propósitos, as atividades realizadas englobam aula expositiva, trabalhos em pequenos grupos, atividades individuais e discussões em sala de aula.

Ainda no que diz respeito à utilização do método de Estudo de Caso no ensino de química, é digna de nota a criação, em 1998, de uma seção específica para o assunto na revista Journal of Chemical Education, uma das mais conhecidas da área. Os editores da revista justificaram a criação desta seção, chamada de Teaching With Problems and Case Studies, alegando a existência, pelo menos até aquele momento, de poucos casos elaborados especificamente para a área de química e adequados para utilização no ensino desta disciplina. Nela são apresentados casos cujas resoluções exigem o conhecimento de princípios de química e de áreas correlatas. São fornecidas aos estudantes situações que, via de regra, eles estão aptos a enfrentar, tanto no que diz respeito ao conhecimento do conteúdo científico, quanto a aquele sobre questões éticas, sociais e econômicas envolvidas no caso. Vale ressaltar, no entanto, que esta seção não se encontra presente em todos os números da revista: no ano de 2003, por ex., nenhum artigo foi nela publicado.

\section{ESTRATÉGIAS PARA UTILIZAÇÃO DE CASOS NO ENSINO SUPERIOR DE CIÊNCIAS}

As estratégias utilizadas para a aplicação do método de Estudo de Caso são diversificadas. Herreid ${ }^{24}$, em 1998, elaborou um esquema de classificação sobre tais estratégias e sugeriu que os casos podiam ser explorados no ensino de ciências através da adoção, pelo professor, dos seguintes formatos:

- de tarefa individual: o caso tem o caráter de uma tarefa que o aluno deve solucionar, que implica na elaboração posterior de uma explicação histórica dos eventos que conduziram à sua resolução;

- de aula expositiva: o caso tem a característica de uma história (caso) contada pelo professor aos seus alunos, de maneira muito elaborada e com objetivos específicos. Este formato foi utilizado por James Conant nas suas aulas de história da química, com o objetivo de apresentar aos estudantes a maneira como o conhecimento científico é construído (ênfase no lado humano da ciência).
Esta experiência foi relatada no livro The Growth of the Experimental Science: An Experimental in General Education ${ }^{15}$. A associação de diálogos e debates pode também ocorrer neste formato de ensino;

- de discussão: o caso é apresentado pelo professor como um dilema. Os alunos são questionados a respeito das suas perspectivas e sugestões com relação à resolução do mesmo;

- de atividades em pequenos grupos: os casos são histórias que devem ser solucionadas e dizem respeito ao contexto social e/ou profissional em que os alunos estão imersos. Uma característica essencial é que os casos são analisados por grupos pequenos de estudantes, que trabalham em colaboração. Os estudantes lêem parte do caso em voz alta, a seguir discutem os elementos apresentados até aquele ponto no caso, listam o que já sabem e elaboram uma agenda de aprendizagem, ou seja, um conjunto de assuntos que eles concordam em pesquisar individualmente antes do encontro seguinte. Este processo se repete até a resolução do caso. O professor, neste contexto, desempenha um papel de facilitador durante as discussões, em vez de um papel didático e diretivo.

São encontrados na literatura exemplos de aplicações de Estudos de Caso nos quais os professores lançam mão de um ou mais dos formatos e também de professores que adotam um dos formatos, com algumas variações. Isto se verifica, por ex., em uma aplicação denominada como método do Caso Interrompido ${ }^{25}$, variante do formato de atividades em pequenos grupos. Neste método, os trabalhos se iniciam quando o professor fornece aos alunos (idealmente divididos em grupos) um caso que trata de um problema que foi realmente enfrentado por pesquisadores de determinada área e solicita que apresentem possíveis caminhos para sua resolução. Depois que os alunos discutem o caso por aproximadamente $15 \mathrm{~min}$, o professor pede que relatem suas idéias a respeito do problema. Em seguida, o professor acrescenta novas informações sobre o caso, o que acarreta em dificuldades adicionais na sua resolução, e pede aos estudantes que imaginem possíveis soluções. Novamente, depois de discussões, eles relatam suas idéias e, então, o professor fornece dados adicionais para suas interpretações. Finalmente, o professor apresenta a resolução sugerida pelos pesquisadores e a confronta com as oferecidas pelos grupos de alunos.

Uma outra variante do formato de atividades em pequenos grupos, denominada método de Múltiplos Casos, foi relatada por Tärnvik ${ }^{26}$. Neste contexto, durante um intervalo de 2 h, vários casos curtos são apresentados e discutidos em sala de aula. Em seguida, a resolução de cada caso é apresentada por alunos, representantes de determinados grupos, e o professor encoraja o estabelecimento de discussões a respeito das soluções encontradas.

Uma variante do formato de aula expositiva, denominada método do Caso Dirigido, que busca principalmente aprofundar e solidificar a compreensão de conceitos ministrados na disciplina em foco, foi descrita por Cliff e Curtin ${ }^{27}$. Neste método o instrutor cria casos curtos e os insere em cada uma das unidades que são apresentadas na tradicional aula expositiva. Cada caso é acompanhado por questões que podem ser respondidas, individualmente ou em grupo, através de consultas a livros ou a anotações realizadas durante as aulas expositivas.

\section{ALGUMAS CONSIDERAÇÕES SOBRE A PRODUÇÃO DE CASOS DESTINADOS AO ENSINO SUPERIOR DE CIÊNCIAS}

Com a paulatina popularização do método de Estudo de Caso no ensino superior de ciências, é cada vez maior o número de professores que se deparam com a necessidade de produzir os casos que serão utilizados nas disciplinas por eles ministradas. Alguns dos aspectos que devem ser considerados para a elaboração de um 
"bom caso" são descritos na literatura e citados a seguir ${ }^{28}$ : um bom caso narra uma história: o fim não deve existir ainda; um bom caso desperta o interesse pela questão: para que um caso pareça real, deve haver um drama, um suspense. O caso deve ter uma questão a ser resolvida; um bom caso deve ser atual: deve tratar de questões atuais, fazendo com que o estudante perceba que o problema é importante; um bom caso produz empatia com os personagens centrais: os personagens devem influenciar na maneira como certas decisões são tomadas; um bom caso inclui citações: é a melhor maneira de compreender uma situação e ganhar empatia para com os personagens. Deve-se adicionar vida e drama a todas as citações; um bom caso é relevante ao leitor: os casos escolhidos devem envolver situações que os estudantes provavelmente saibam enfrentar. Isto melhora o fator empatia e faz do caso algo que vale a pena estudar; um bom caso deve ter utilidade pedagógica: deve ser útil para o curso e para o estudante; um bom caso provoca um conflito: a maioria dos casos é fundamentada sobre algo controverso; um bom caso força uma decisão: deve haver urgência e seriedade envolvida na resolução dos casos; um bom caso tem generalizações: deve ter aplicabilidade geral e não ser específico para apenas uma curiosidade; um bom caso é curto: os casos devem ser suficientemente longos para introduzir os fatos de um caso, mas não tão longos que possam provocar uma análise tediosa.

$\mathrm{Na}$ dissertação de mestrado de uma das autoras deste trabalho ${ }^{8}$ são encontrados casos que foram elaborados seguindo as recomendações citadas. A título de ilustração, um dos referidos casos, o Caso Ameaça nos Laranjais, encontra-se no Quadro 1 e nele são destacados alguns dos elementos que foram apontados como necessários a um "bom caso".

Além da sugestão de incorporação dos elementos acima citados nos casos produzidos, são também encontradas na literatura menções às etapas que costumam ser seguidas durante o processo de elaboração dos mesmos ${ }^{29}$, que incluem: a escolha do assunto principal a ser destacado no caso. Este deve ser relevante dentro do contexto da disciplina a ser ministrada e, de preferência, deve também estar relacionado com questões atuais e/ou controversas, tais como aquecimento global, desastres ambientais, questões sociais etc. Estas questões atrairão a atenção dos alunos e despertarão o interesse na resolução dos casos; a elaboração de uma lista com todos os conceitos/habilidades/atitudes que se pretende abordar através da aplicação do caso, para que na sua construção sejam inseridas questões ou situações que possam conduzir ao desenvolvimento de tais aspectos; a elaboração de uma lista dos possíveis personagens do caso, que deverão apresentar características pertinentes à situação geral apresentada no caso; concluída uma versão adequada do caso, há a elaboração de uma série de questões para discussão em sala de aula. Estas questões auxiliarão o aluno a reconhecer aspectos importantes, passíveis de serem discutidos a partir da resolução do caso.

Cabe ainda destacar que o artigo científico, aqui entendido como um texto cuja organização é destacada pela divisão em seções introdução, materiais e métodos, resultados e discussão - o qual descreve resultados originais de uma investigação científica ${ }^{30}$, tem sido utilizado por vários autores como fonte de inspiração para a produção de casos destinados ao ensino superior de ciências ${ }^{13,22,31,32}$. Tanto artigos clássicos ${ }^{31}$ como contemporâneos ${ }^{13,22}$ têm sido empregados nesta empreitada. A utilização deste material abre perspectivas para que jargões científicos, técnicas instrumentais, gráficos e tabelas sejam incorporados ao caso, conforme ocorre, por ex., nos trabalhos relatados por Camill" ${ }^{22}$ e Cornely ${ }^{13}$, intitulados "Using Journal Articles in an Environmental Biology Course" e "Journal Articles as Case Studies", respectivamente.

Herreid $^{31}$ salientou ainda que as informações contidas no arti-

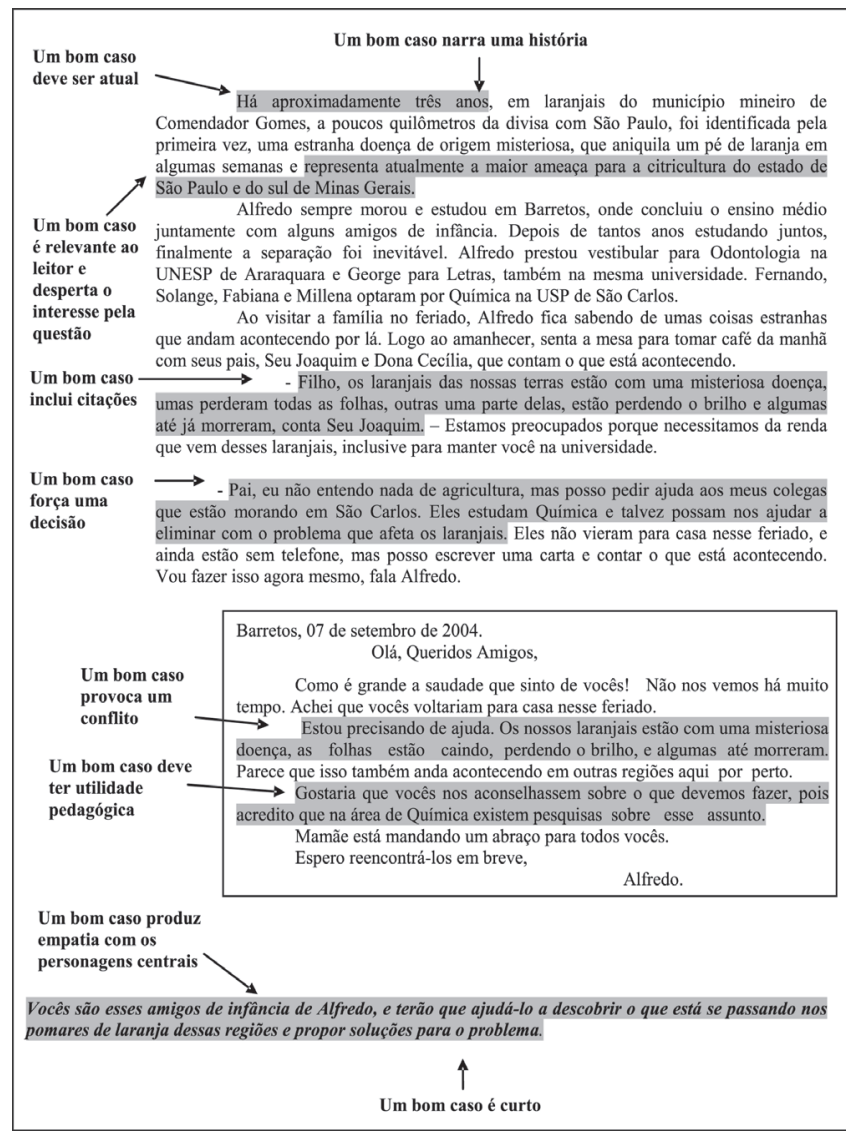

Quadro 1. Caso Ameaça nos Laranjais e identificação de elementos que estão de acordo com as recomendações de Herreid ${ }^{28}$ sobre como se elaborar um "bom caso"

go científico podem também facilitar a produção de casos que favoreçam a promoção do entendimento dos alunos sobre o processo de construção da ciência. Assim como Herreid ${ }^{31}$, Galucci ${ }^{32}$ e Santos et al. ${ }^{33}$ também destacaram o papel importante que o artigo científico pode desempenhar quando se pretende fomentar este tipo de entendimento/habilidade nos alunos de graduação.

Nesta perspectiva, Gallucci ${ }^{32}$ relatou uma experiência em que alunos de um curso introdutório de biologia leram o artigo intitulado "A Randomized, Controlled Trial of the Effects of Remote, Intercessory Prayer on Outcomes in Patients Admitted to the Coronary Care Unit" publicado na revista Archives of Internal Medicine, que serviu de base para questionamentos acerca do método científico empregado na execução da pesquisa. Santos et al. ${ }^{33}$, por sua vez, relataram uma experiência realizada em uma disciplina de físico-química na qual os alunos leram artigos científicos da área. Durante a realização da atividade os alunos fizeram questionamentos relacionados não apenas ao conteúdo científico dos artigos como também sobre o seu processo de produção e, consequientemente, sobre o próprio processo de construção da ciência.

\section{USO DO MÉTODO DE ESTUDO DE CASO NO ENSINO SUPERIOR DE QUÍMICA}

Algumas iniciativas sobre a utilização do método de Estudo de Caso no ensino superior de química, relatadas nas revistas Journal of Chemical Education, The Chemical Educator, Chemistry Education Research and Practice (antigo University Chemistry Education), foram por nós analisadas visando oferecer ao leitor uma visão geral sobre a sua utilização particularmente nesta área. 
Localizamos no Journal of Chemical Education, no período compreendido entre janeiro de 1980 a abril de 2006, 17 trabalhos que tratam do método. Em cada uma das revistas The Chemical Educator e Chemistry Education Research and Practice foram localizados 4 artigos, nos períodos compreendidos entre janeiro de 1996 a abril de 2006 e setembro de 1997 a janeiro de 2006, respectivamente.

A análise dos artigos presentes nestas 3 revistas nos permitiu verificar as subáreas/áreas correlatas da química em que o método de Estudo de Caso foi empregado, assim como os objetivos buscados com sua aplicação. Também estabelecemos relações entre as estratégias de ensino relatadas nos artigos para a aplicação do método e aquelas citadas anteriormente, indicadas por Herreid ${ }^{24}$, e tomamos conhecimento das impressões de alunos e de professores sobre o método, apresentadas nos referidos artigos.

\section{Aplicação do método de Estudo de Caso nas diferentes subáreas/áreas correlatas da química e os principais objetivos buscados}

A Tabela 1 apresenta o número de trabalhos encontrados nos periódicos mencionados acima e as temáticas principais abordadas, assim como seus principais objetivos. É importante ressaltar que, dos 25 trabalhos localizados, alguns deles se relacionam a 2 subáreas/ áreas correlatas da química, simultaneamente, e também possuem mais de um objetivo. Esta é a razão pela qual o total de trabalhos apresentados e o número de objetivos na Tabela 1 ultrapassa o número total de 25 trabalhos.

Cabe ainda esclarecer que um dos trabalhos, intitulado "Who is Responsible for a Fraud: An Exercise Examining Research Misconduct and the Obligations of Authorship Through Case Studies" ${ }^{34}$, não se destina a nenhuma das subáreas/áreas correlatas da química citadas na Tabela 1; é o único que se encontra na categoria "Outra". O referido trabalho visa o desenvolvimento do senso crítico dos alunos a respeito de algumas questões éticas que permeiam o dia-a-dia dos cientistas, como questões de autoria indevida em artigos científicos e publicação de dados fraudulentos.

Na Tabela 1, abaixo de cada subárea/área correlata da química está citada a quantidade de trabalhos localizados que a ela se relaciona. Os números distribuídos no restante da Tabela 1 indicam a quantidade de trabalhos que apresentaram um determinado objetivo em uma mesma subárea/área correlata. Cabe esclarecer que as subáreas/áreas correlatas da química estão identificadas na Tabela 1 por abreviações: BIOQ (bioquímica), FISQ (físico-química), QAM (química ambiental), QANA (química analítica), QG (química geral), QAI (química aplicada à indústria), QO (química orgânica) e QI (química inorgânica).
A partir dos dados apresentados na Tabela 1, verificamos um maior número de trabalhos relacionados à química geral (6), sendo que 5 dos 6 trabalhos localizados tinham como principal objetivo favorecer a compreensão de conceitos introdutórios de química geral aos alunos ${ }^{6,35-37}$. Assim, embora outros objetivos também tenham sido citados nestes trabalhos (estímulo à capacidade de tomada de decisão dos alunos, desenvolvimento da habilidade em resolver problemas, de comunicação oral e escrita e de trabalho em grupo), os números sugerem uma preocupação existente entre os professores em utilizar o método de Estudo de Caso para introduzir princípios de química aos estudantes.

Trabalhos relacionados à química ambiental e físico-química também foram encontrados em número significativo. No que diz respeito à química ambiental, a quantidade considerável de trabalhos localizados, em relação a outras subáreas/áreas correlatas, pode estar relacionada ao fato de que, nesta subárea específica, são abundantes as possibilidades de abordagem de problemas do chamado "mundo real" dos estudantes, o que torna possível a discussão dos aspectos sociais, ambientais, econômicos ou éticos envolvidos no problema. Desta forma, não é surpreendente que o objetivo mais apontado nos trabalhos que envolvem a temática tenha sido o desenvolvimento da capacidade de tomada de decisão sobre questões ambientais ${ }^{5,38-40}$.

A quantidade significativa de artigos que tratam de tópicos de físico-química ${ }^{17,41,42}$ pode estar relacionada à existência de uma preocupação, por parte de professores desta disciplina, em utilizar estratégias que minimizem as grandes dificuldades que os alunos têm em compreendê-la. Tais dificuldades, segundo Belt et $a l .^{42}$, se devem, muitas vezes, à pouca habilidade dos alunos com relação à matemática, pré-requisito para compreensão da físico-química. Vale ressaltar que 2 dos artigos relacionados a esta subárea, intitulados "A Novel Spiral Approach to Introductory Chemistry Using Case Studies of Chemistry in the Real World" ${ }^{43}$ e "Case Studies as a Basis for Discussion Method Teaching in Introductory Chemistry Courses"16, relacionam assuntos de química geral e físico-química. Estes trabalhos tiveram como principal objetivo favorecer a compreensão dos alunos a respeito de tópicos concernentes a estas áreas.

Foram localizados 4 trabalhos relacionados à química analítica e à bioquímica. Dos 4 artigos que abordavam tópicos de química analítica ${ }^{7,44}, 2$ também abordavam questões relacionadas a outras subáreas de conhecimento da química: "Well Wishes. A Case on Septic Systems and Well Water Requiring In-Depth Analysis and Including Optional Laboratory Experiments" ${ }^{45}$ e "Cases of Two Chemical Criminals: Drug-Induced Hypertension and Respiratory Paralysis" ${ }^{46}$. O primeiro refere-se a tópicos relacionados à química analítica e à química ambiental e visa, além da compreensão de

Tabela 1. Síntese dos trabalhos relacionados às diversas subáreas/áreas correlatas da química e seus principais objetivos, segundo o levantamento bibliográfico realizado nos periódicos Journal of Chemical Education, The Chemical Educator e Chemistry Education Research and Practice, no período de janeiro de 1980 a abril de 2006

\begin{tabular}{|c|c|c|c|c|c|c|c|c|c|}
\hline $\begin{array}{l}\left.\text { Subáreas/Áreas Correlatas - ( } \mathrm{N}^{\circ} \text { de trabalhos }\right) \\
\text { Objetivos }\end{array}$ & $\begin{array}{c}\text { BIOQ } \\
(4)\end{array}$ & $\begin{array}{l}\text { FÍSQ } \\
(5)\end{array}$ & $\underset{(5)}{\text { QAM }}$ & $\begin{array}{c}\text { QANA } \\
\text { (4) }\end{array}$ & $\begin{array}{l}\text { QG } \\
(6)\end{array}$ & $\begin{array}{c}\text { QAI } \\
(3)\end{array}$ & $\begin{array}{l}\text { QI } \\
(0)\end{array}$ & $\begin{array}{l}\text { QO } \\
(3)\end{array}$ & $\begin{array}{l}\text { Outra } \\
(1)\end{array}$ \\
\hline Introduzir conteúdos específicos & 3 & 4 & 3 & 3 & 5 & 3 & - & 2 & - \\
\hline Estimular a capacidade de tomada de decisão & - & - & 4 & - & 1 & 1 & - & - & - \\
\hline Demonstrar a aplicação de conceitos químicos na prática & - & - & - & 1 & - & 1 & - & - & - \\
\hline Desenvolver a habilidade em resolver problemas & 2 & 3 & - & 2 & 1 & - & - & 1 & - \\
\hline Desenvolver a habilidade de comunicação oral e escrita & - & 2 & 1 & 1 & 1 & 1 & - & - & - \\
\hline Desenvolver a habilidade de trabalho em grupo & - & 1 & 1 & 1 & - & 1 & - & - & - \\
\hline Desenvolver o pensamento crítico & 1 & 1 & 3 & 1 & 2 & 1 & - & 1 & 1 \\
\hline
\end{tabular}

BIOQ = Bioquímica; FÍSQ = Fisico-Química; QAM = Química Ambiental; QANA = Química Analítica; QG = Química Geral; QAI = Química Aplicada à Indústria; QI = Química Inorgânica; QO = Química Orgânica; Outra = Outras Subáreas/Áreas Correlatas da Química. 
princípios e técnicas analíticas, o desenvolvimento de habilidades em resolver problemas e de pensamento crítico dos alunos em relação ao impacto ambiental provocado pela ação do homem. No segundo, são abordados tópicos relacionados à química analítica e bioquímica. São descritos casos clínicos que exigem considerações de aspectos bioquímicos e de técnicas analíticas para suas resoluções. Com exceção do desenvolvimento da capacidade de tomada de decisão, observamos na Tabela 1 que todos os outros objetivos foram citados em pelo menos um dos trabalhos relacionados à química analítica.

Em relação aos trabalhos com abordagem de tópicos de bioquímica ${ }^{46-49}, 2$ tratam de conteúdos de bioquímica e química orgânica, simultaneamente. O primeiro, intitulado "Thalidomide Makes a Comeback: A Case Discussion Exercise That Integrates Biochemistry and Organic Chemistry", como o próprio título sugere, associa bioquímica e química orgânica e tem como principais propósitos, além da aprendizagem de conteúdos científicos, estimular o pensamento crítico dos estudantes através da análise de riscos e benefícios envolvidos na distribuição do medicamento talidomida ${ }^{49}$. O segundo, intitulado "Molecular Moddeling in the Undergraduate Chemistry Curriculum: The Use of $\beta$-Lactams as a Case Study", introduz conceitos de modelagem molecular e química computacional ${ }^{47}$. Identificamos a presença dos seguintes objetivos nos trabalhos relacionados à bioquímica: introduzir conteúdos específicos da área, desenvolver a habilidade em resolver problemas e pensamento crítico.

Trabalhos relacionados à química aplicada à indústria e à química orgânica foram localizados na mesma proporção. Em relação à química aplicada à indústria, os 3 trabalhos localizados tinham como um dos objetivos principais a aprendizagem sobre processos industriais $^{50-52}$. Porém, nesta subárea da química, outros objetivos também foram apontados em, pelo menos, um dos trabalhos analisados: tomada de decisão, demonstração da aplicação de conceitos químicos na prática, desenvolvimento de habilidades de comunicação oral e escrita, trabalho em grupo e pensamento crítico.

Os trabalhos que abordavam tópicos de química orgânica ${ }^{19,47,49}$ objetivavam a aprendizagem de conteúdo, o desenvolvimento de habilidades em resolver problemas e pensamento crítico. Não foi localizado nenhum trabalho relacionado à área de química inorgânica.

\section{Diferentes maneiras como professores de química empregaram o método de Estudo de Caso em suas aulas}

No conjunto de artigos analisado também são descritas as formas como professores de química empregaram o método de Estudo de Caso em suas aulas e, em alguns deles, a avaliação desta metodologia é realizada pelos alunos ou pelos professores. De maneira geral, podemos afirmar que os formatos utilizados estão entre aqueles citados por Herreid ${ }^{24}$, em seu trabalho de revisão que trata das possíveis maneiras de ensinar via utilização de casos. A Tabela 2 mostra a quantidade de trabalhos em que os diferentes formatos foram utilizados, sendo importante considerar que em alguns artigos são citados mais de um formato para a realização das atividades e que em outros, estes formatos não são especificados. Por esta razão o total de trabalhos apresentados na Tabela 2 ultrapassa o número de 25 trabalhos.

Como podemos observar na Tabela 2, os formatos de discussão e de pequenos grupos foram os mais utilizados nas atividades com Estudos de Casos. No que diz respeito à discussão, verificamos que este formato é freqüentemente associado aos outros formatos de ensino. Os trabalhos de Dewprashad et al. ${ }^{37}$ e Krow e Krow ${ }^{39}$ podem ser citados como exemplo da aplicação do formato de dis-
Tabela 2. Quantidade de trabalhos que utilizaram os diferentes formatos de ensino durante as atividades com Estudos de Casos, segundo o levantamento bibliográfico realizado nos periódicos Journal of Chemical Education, The Chemical Educator e Chemistry Education Research and Practice, no período de janeiro de 1980 a abril de 2006

\begin{tabular}{lc}
\hline $\begin{array}{l}\text { Formatos de ensino } \\
\text { classificados por Herreid }^{24}\end{array}$ & $\begin{array}{c}\text { Quantidade } \\
\text { de trabalhos }\end{array}$ \\
\hline Aula expositiva & 4 \\
Discussão & 16 \\
Pequenos grupos & 15 \\
Tarefa individual & 10 \\
Não especifica formato & 2 \\
\hline
\end{tabular}

cussão aliado aos outros formatos apresentados por Herreid ${ }^{24}$. No primeiro, tanto o formato de discussão, quanto o de atividades em pequenos grupos são empregados durante a atividade. O trabalho consistiu no uso de casos clínicos com resultados de exames laboratoriais, que tinha como objetivo a aprendizagem a respeito dos princípios químicos envolvidos no diagnóstico médico e nas opções de tratamento para o paciente. Estes casos foram elaborados de forma compreensível para alunos que não fossem da área de medicina. Nesta atividade, os estudantes foram divididos em grupos e posteriormente iniciou-se uma discussão sobre o caso clínico com o intuito de fornecer soluções para o paciente. No segundo trabalho, a atividade proposta teve duração de 4 semanas e dizia respeito a problemas relacionados à qualidade ambiental. A sala de aula, composta por 25 alunos, foi dividida em 5 grupos. Depois que o problema foi introduzido se iniciou uma discussão sobre o assunto e durante 2 semanas o professor apresentou os conceitos químicos básicos relacionados à radiação. Os grupos ficaram livres para desenvolver estratégias para responder suas questões. No entanto, individualmente, os alunos se responsabilizaram pelo material necessário e pela investigação de novos termos e respostas para questões que requeriam análise, aplicação ou síntese de informações. Com base nesta descrição, podemos observar que todos os formatos propostos por Herreid ${ }^{24}$ foram aplicados para a realização da atividade proposta por Krow e Krow ${ }^{39}$.

Com relação ao formato de atividades em pequenos grupos, este também foi encontrado em número significativo. Podemos citar como exemplo os trabalhos de Cheng $^{38}$ em disciplina de química ambiental e de Conerly ${ }^{48}$ em disciplina de bioquímica. No primeiro, foram elaborados casos que tratavam de graves problemas de poluição em Hong Kong, tais como a quantidade e os tipos de poluentes produzidos por uma indústria e seu impacto ambiental. A atividade teve como objetivo proporcionar aos estudantes a oportunidade de aprender sobre métodos disponíveis para sanar tal situação, a partir de uma análise, realizada pelos grupos, sobre as vantagens e desvantagens por eles oferecidas. No segundo, a sala de aula foi dividida em grupos de 3 a 5 estudantes. Para cada grupo foi atribuído, aleatoriamente, um caso diferente. Estes casos descreviam os sintomas de um paciente que padecia de uma doença metabólica, relacionada à não eficiência de determinada enzima, e os resultados de alguns exames aos quais ele havia sido submetido. A descrição do caso era seguida por uma série de questões que visavam favorecer o entendimento do aluno sobre as reações químicas que ocorrem nas células.

Foram localizados 10 artigos que utilizaram a tarefa individual como formato de ensino. Como exemplo, podemos citar o trabalho de Ringan e Grayson ${ }^{47}$, em que exercícios individuais foram aplicados com o objetivo de introduzir conceitos de modelagem molecular e química computacional. Ou seja, a atividade objetivava 
oferecer aos estudantes oportunidade de utilizarem seus conhecimentos sobre modelagem molecular para examinar problemas específicos de química orgânica e bioquímica. Isso permitia ao estudante a investigação sobre conceitos tais como quiralidade e análise conformacional (tópicos previamente discutidos em uma abordagem teórica).

Com relação ao formato de aula expositiva, apenas 4 trabalhos foram localizados. Todos associavam a tradicional aula expositiva a outros formatos de ensino. Tal fato pode estar relacionado às insistentes recomendações presentes na literatura sobre a introdução de novas estratégias de ensino capazes de atrair o interesse dos estudantes. Neste contexto, Hodges e Harvey ${ }^{19}$ lembraram que a aula expositiva, de forma isolada, pode ser um útil veículo para transmissão de informações, mas dificilmente envolve os estudantes no processo de integração de idéias e conceitos. Estes autores desenvolveram o trabalho intitulado "Using Collaborative Cases in Organic Chemistry", que descreve o uso do método de Estudo de Caso como parte de uma abordagem de aprendizagem colaborativa para o ensino de química orgânica. A atividade foi realizada da seguinte forma: durante a aula os alunos discutiam suas respostas para o problema proposto, dentro de seus pequenos grupos, e depois a discussão se estendia à classe inteira. As aulas expositivas, usualmente não ultrapassavam $15 \mathrm{~min}$, e eram usadas para esclarecer conceitos e idéias equivocadas.

Dois dos artigos analisados não especificavam nenhum tipo de formato de ensino. Como exemplo, podemos citar o trabalho de Ciliberto et al. ${ }^{44}$ intitulado "A Scientific Approach to Cultural Heritage Preservation: A Case Study of Vandalistic Acts on Important Roman Mosaics", que mostra a importância e o papel dos métodos analíticos na resolução de questões relacionadas à restauração de objetos históricos, no caso um importante mosaico romano depredado por vândalos. Este trabalho teve como principal objetivo mostrar o importante papel de técnicas analíticas na resolução de questões relevantes sobre restaurações de objetos pertencentes ao patrimônio histórico. No entanto, não apresenta nenhum formato de ensino, sendo o caso descrito e solucionado pelos próprios autores.

\section{Impressões de alunos e professores sobre o uso de Estudos de Casos em disciplinas de química}

No que diz respeito à avaliação realizada nestes trabalhos, por alunos e professores, sobre a aplicação de Estudos de Casos no ensino de química, observamos que dos 25 artigos localizados, 5 apresentam somente as opiniões dos estudantes a respeito da atividade, 11 mostram somente as impressões dos professores, 5 apresentam as impressões tanto dos professores como dos alunos e 4 não apresentam avaliação. Alguns exemplos de trabalhos nos quais esta avaliação é feita são descritos a seguir.

No trabalho de Cornely ${ }^{48}$, os alunos envolvidos no estudo utilizaram uma escala Likert de 5 pontos, variando entre "concordo fortemente" e "discordo fortemente", para avaliar as atividades realizadas no curso. Para a afirmação "O Estudo de Caso foi um exercício útil" foram obtidas $45 \%$ de respostas "concordo fortemente", $31 \%$ de respostas "concordo", $18 \%$ de respostas "neutro" e $6 \%$ de respostas "discordo". Com estes resultados verifica-se que uma parcela significativa de alunos apresentou concordância (76\%) em relação à utilidade do método de Estudo de Caso na sua aprendizagem. Comentários feitos por estes estudantes também revelaram suas impressões sobre a atividade. Um deles, relacionado ao trabalho em grupo, é descrito a seguir e revela a satisfação do aluno com a atividade proposta e o reconhecimento da sua aprendizagem ao realizar este tipo de atividade.
"Eu realmente gostei do final do Estudo de Caso. Isso não havia acontecido até eu discutir com meu grupo. Nós todos estávamos contribuindo igualmente e aí eu percebi o quanto eu havia realmente aprendido".

Para avaliar a atividade com Estudos de Casos, Walczak e Lant ${ }^{45}$ solicitaram aos alunos que respondessem a seguinte questão: qual conceito relacionado a este caso você provavelmente será capaz de recordar depois deste período (por ex., depois do semestre)? Se algum, qual a relevância que ele tem para você? O artigo apresenta algumas das respostas dos estudantes e uma delas é citada a seguir:

\begin{abstract}
"Depois de trabalhar com este caso, eu aprendi alguns dos efeitos sobre a saúde relacionados a elevados níveis de nitrato na água potável (...). Além disso, eu pessoalmente nunca considerei os aspectos negativos do uso de fertilizantes químicos sobre os gramados. Esse caso mostra que as pessoas devem ser atentas sobre o que elas colocam em seu solo, já que isto pode contaminar sua própria água potável".
\end{abstract}

Bennett e Cornely ${ }^{49}$, ao perguntarem aos alunos se a atividade com casos os havia ajudado a compreender como a química orgânica e a bioquímica poderiam ser aplicadas em problemas reais, verificaram que $20 \%$ responderam que os casos funcionaram muito bem, $67 \%$ acharam que funcionaram bem e $12 \%$ acharam que o caso foi adequado. Quando perguntaram como o caso os havia ajudado a compreender as questões sociais acerca da distribuição da droga, verificaram que $48 \%$ responderam que o caso funcionou muito bem, $48 \%$ que funcionou bem e $4 \%$ que foi adequado. Segundo os autores, não foram conduzidas pesquisas formais, mas discussões ocorridas após o exercício com o Estudo de Caso indicaram que os estudantes estavam bastante interessados na atividade.

Quanto às impressões dos professores a respeito das atividades com Estudos de Casos, além do entendimento dos alunos sobre conceitos embutidos nos conteúdos ministrados nas disciplinas, alguns autores mencionaram diversos tipos de habilidades por eles adquiridas. Al-Khlaifat e AlRifai ${ }^{41}$, afirmam que o Estudo de Caso contribuiu significativamente para melhorar o repertório de habilidades dos estudantes, que incluem: identificar os objetivos desejados a serem atingidos a partir de um Estudo de Caso particular; identificar os dados e detalhes necessários para direcionar um problema; melhorar as habilidades em resolver problemas; desenvolver habilidades de trabalho em grupo e de comunicação oral etc. Cornely ${ }^{48}$ comenta que os estudantes estão acostumados a trabalhar independentemente em suas atividades e o exercício com Estudo de Caso forneceu a oportunidade de trabalharem colaborativamente com os colegas. Pois, para resolver o caso com sucesso, os alunos tiveram que se envolver ativamente na busca de soluções para o problema. Conclui ainda que o uso de Estudos de Casos em um curso de bioquímica encoraja os estudantes a participarem ativamente da aprendizagem, ao invés de atuarem como receptores passivos de informações.

De modo geral, as impressões coletadas pelos professores sobre as atividades com casos apontam-nas como satisfatórias e prazerosas. Como exemplo podemos citar os trabalhos de Dewprashad et al. ${ }^{37} \mathrm{e}$ Duprey et $a l .^{52}$. No primeiro, que descreve a aplicação de casos clínicos para ensinar química geral aos estudantes, os autores afirmam que quase todos os estudantes mostraram entusiasmo e elevado nível de participação durante a atividade com Estudo de Caso. No segundo, que está relacionado a uma atividade com um grupo de estudantes sobre a química das fragrâncias, os autores observaram que os grupos mostraram grande entusiasmo e iniciativa, particularmente quando combinavam e promoviam a comercialização de sua fragrância. Afirmam ainda que o nível de participação dos estudan- 
tes foi bastante satisfatório, uma vez que tópicos desta natureza aumentam a motivação dos estudantes, quando percebem a relevância do assunto para o chamado "mundo real".

Em contrapartida, Cheng ${ }^{38}$ afirma que se deve ter um cuidado especial para a efetiva implementação de metodologias de ensino menos convencionais que envolvam estudantes passivos e imaturos. Via de regra, tais alunos mostram-se resistentes a novos formatos de ensino e apresentam dificuldades em formular suas opiniões.

\section{APLICAÇÃO DO MÉTODO DE ESTUDO DE CASO NA DISCIPLINA COMUNICAÇÃO E EXPRESSÃO EM LINGUAGEM CIENTÍFICA II}

O método de Estudo de Caso foi aplicado na disciplina Comunicação e Expressão em Linguagem Científica II, disciplina teórica, 2 créditos, oferecida para alunos matriculados no segundo semestre do curso de Bacharelado em Química do Instituto de Química de São Paulo - Universidade de São Paulo. Esta disciplina, que não trata de conteúdos específicos de química, visa o desenvolvimento de habilidades de comunicação oral dos alunos e da capacidade de busca nas diversas fontes de informação de interesse para os químicos. Busca ainda consolidar o conhecimento de assuntos abordados na disciplina Comunicação e Expressão em Linguagem Científica I, que a antecede, que apresenta as diversas formas como a ciência é divulgada, os tipos de artigos científicos existentes e as características peculiares de cada um deles e questiona a importância da comunicação para o profissional da área de química ${ }^{53}$. Neste contexto, os alunos realizaram estudos de casos que proporcionaram a discussão, principalmente, de questões de caráter sócio-científico.

\section{Produção dos casos e aplicação da proposta}

Foram elaborados 5 casos distintos, nos moldes propostos por Herreid $^{28}$, denominados: Praga do Coqueiro, Caso das Próteses, Ameaça nos Laranjais, Poluição em Rondônia e Doença de Granja. O caso Ameaça nos Laranjais encontra-se ilustrado no Quadro 1 e os demais estão disponíveis na dissertação de mestrado de uma das autoras deste trabalho ${ }^{8}$.

Pesquisas recentes publicadas na revista Pesquisa FAPESP serviram como fonte de inspiração para a elaboração dos casos. Para a elaboração do caso Ameaça nos Laranjais, por ex., nos pautamos em informações contidas na reportagem "Risco de Enfarto nos Laranjais", publicada no $n^{\circ} 85$ da revista. Os casos foram estruturados de modo que apresentassem em seu contexto questões sociais, ambientais, econômicas e/ou éticas, com o intuito de estimular no aluno a capacidade de tomar decisões diante de problemas da vida real e de argumentar a favor destas decisões. Os alunos recebiam, juntamente com cada um dos casos, um "Guia Para Análise e Resolução dos Casos", que tinha como objetivo auxiliá-los na discussão e análise dos casos. A estrutura deste guia é semelhante àquela utilizada por Waterman ${ }^{11}$, em seu trabalho "Investigative Case Study Approach For Biology Learning".

No primeiro dia de aula do bimestre os alunos foram informados que as atividades do período iriam envolver: o trabalho com casos investigativos; a preparação, em grupo, de uma apresentação oral sobre a resolução dos mesmos; a produção, em grupo, de um "diário do caso", que deveria deixar claro ao leitor o processo que os conduzira à resolução do caso, incluindo informações obtidas neste processo e reflexões sobre o seu andamento; a produção individual de um texto sobre o assunto envolvido no caso, com formato e linguagem direcionada a alunos do ensino médio. Este texto seria, após a conclusão do semestre, submetido para publicação na Revista Eletrônica do Centro de Divulgação Científica e Cultural
(CDCC). O CDCC é um órgão pertencente à Universidade de São Paulo e vincula-se à Pró-Reitoria de Cultura e Extensão Universitária, ao Instituto de Física de São Carlos e ao Instituto de Química de São Carlos. Alguns textos foram, de fato, aceitos para publicação e encontram-se disponíveis no site da revista ${ }^{54}$.

Ainda no primeiro dia de aula foram formados 15 grupos, sendo 10 grupos de 4 alunos, 4 grupos de 3 alunos e 1 grupo de 5 alunos. Os casos foram distribuídos aleatoriamente, de modo que cada caso foi estudado por 3 grupos diferentes. Nesta ocasião os alunos foram orientados sobre as possíveis maneiras de proceder para a resolução dos casos, passaram a utilizar o "Guia Para Análise e Resolução de Casos" e fizeram um levantamento de idéias sobre o que "se sabia" e o que "ainda se precisava saber" sobre o caso. Depois desta discussão inicial foi solicitado aos alunos que pesquisassem individualmente, nas diversas fontes de informações, sobre o assunto envolvido no caso. O material localizado deveria ser trazido para os 2 próximos encontros, que ocorreriam em sala de aula. Nestes encontros, que tiveram duração de $2 \mathrm{~h}$ cada, os alunos responderam, por escrito, questões relacionadas ao caso. Estas foram elaboradas tomando por base o modelo normativo de tomada de decisão de Kortland ${ }^{55}$, que evidencia etapas capazes de facilitar a tomada de decisão pelos alunos com relação a um determinado assunto. Assim, as questões formuladas visavam facilitar o processo de busca coletiva por possíveis alternativas de solução para o caso e de tomada de decisão sobre aquela que deveria ser adotada. Argumentos, capazes de sustentar a decisão escolhida, deveriam também ser apresentados pelos estudantes na resolução das questões.

Durante o bimestre foram reservados momentos para que os alunos falassem sobre o desenvolvimento das atividades na busca para resolução dos casos e sanassem as suas eventuais dúvidas. Também foram estabelecidos horários de monitoria semanais, com $2 \mathrm{~h}$ de duração. Na última semana do bimestre foi organizado um mini-simpósio, realizado em horário extraclasse, durante um intervalo de 4 dias, totalizando 7:30 h de duração, sendo 1:30 h para cada um dos horários reservados. Neste mini-simpósio foram apresentadas as resoluções dos casos por um dos membros de cada grupo, em um intervalo de 15 a 20 min. A programação do minisimpósio foi elaborada de tal forma que 3 casos diferentes foram apresentados em cada noite. Ou seja, em nenhuma das ocasiões verificou-se a apresentação da resolução de casos idênticos. O membro do grupo responsável por apresentar oralmente a resolução do caso era sorteado $15 \mathrm{~min}$ antes do início da apresentação. Esperava-se, com isso, garantir que todos os integrantes da equipe estivessem devidamente preparados para apresentar seus argumentos sobre a resolução escolhida para o caso. Cabe ainda esclarecer que os alunos foram convidados a assistir a todas as apresentações do mini-simpósio, tendo, no entanto, que comparecer, obrigatoriamente, apenas àquelas apresentações programadas para o mesmo período reservado para o seu grupo.

Em todos os dias do mini-simpósio, após a apresentação da resolução de cada um dos casos, a professora solicitou aos demais grupos presentes que procurassem sanar suas possíveis dúvidas e que fizessem questionamentos com relação à pertinência da alternativa apontada pela equipe expositora como a melhor solução para o caso. Ao final das apresentações, cada grupo de alunos foi também indagado pela professora a respeito de suas impressões e de possíveis sugestões em relação à atividade realizada.

Para a aplicação da proposta foram utilizadas aproximadamente $10 \mathrm{~h}$ em sala de aula (horário normal), sendo que a maior parte deste tempo foi destinada a discussões realizadas em grupo pelos alunos e à resolução de questões relacionadas aos casos. Para a realização do mini-simpósio foram necessárias 7:30 h de atividades fora do horário normal de aula. No entanto, cada um dos alu- 
nos teve que comparecer a apenas 1:30 h do mini-simpósio, uma vez que estes tinham a obrigação de participar somente daquelas apresentações programadas para o mesmo período reservado para o seu grupo. Ou seja, os alunos dedicaram 11:30 h para as atividades realizadas em sala de aula. Porém, acreditamos que um tempo considerável tenha sido utilizado pelos alunos em atividades extraclasse, que envolveram: buscas por informações para resolução dos casos, preparação do "diário do caso", redação dos textos para submissão à Revista Eletrônica do CDCC e preparação das apresentações orais.

\section{Considerações sobre o processo de aplicação da proposta e os resultados dela provenientes}

O acompanhamento das atividades dos alunos durante o trabalho de resolução dos casos e a análise do material por eles produzido nos permitem tecer aqui algumas considerações sobre o processo de aplicação da proposta e os resultados dela provenientes.

No que diz respeito às soluções encontradas pelos grupos, temos que considerar que a natureza dos casos não exigia um método único e exato de solução. Por esta razão, alguns casos foram solucionados de maneiras distintas e outros de maneira idêntica. No Caso das Próteses, por ex., os 3 grupos chegaram à mesma conclusão sobre a resolução do caso. No entanto, os 3 grupos que solucionaram o Caso Doença de Granja chegaram a conclusões distintas sobre a melhor solução para o caso.

Um único grupo não entregou o "diário do caso". A partir da análise dos diários observamos que os estudantes buscaram informações em diversas fontes. De maneira geral, a Internet foi a fonte mais utilizada. Porém, os grupos também recorreram a outros recursos, como livros, jornais, teses, troca de e-mails e entrevistas com profissionais de áreas relacionadas aos assuntos dos casos. Também é importante destacar a ampla utilização de artigos científicos, algumas vezes localizados em bancos de dados como o Scielo ou Web of Science, o que sugere uma preocupação dos alunos na busca de informações confiáveis e bem fundamentadas. A partir destas observações, verificamos a adequação da proposta à disciplina Comunicação e Expressão em Linguagem Científica II, uma vez que contemplou um dos seus principais objetivos, que é apresentar aos alunos as diversas fontes de informação em ciência.

A partir das observações que fizemos das discussões ocorridas entre os alunos após as apresentações orais, percebemos, de maneira geral, que os questionamentos daqueles que estavam assistindo às apresentações, dirigidos aos colegas expositores das resoluções dos casos, eram muito limitados e se resumiam a simples perguntas sobre definições gerais de termos específicos do caso e sobre algumas curiosidades inerentes ao assunto que, por sinal, eram respondidas prontamente pelos grupos. Isso se deve, provavelmente, ao fato de, na tentativa de tornar a atividade mais interessante e menos cansativa, termos distribuído as apresentações, de tal modo que reunissem em cada ocasião 3 grupos com casos distintos. Aventamos esta hipótese uma vez que verificamos uma discussão bem mais rica quando existiam na platéia alunos que haviam solucionado o mesmo caso que estava sendo exposto ${ }^{56}$. Assim, consideraremos a possibilidade de distribuir os casos de maneira diferente (solicitando que a resolução de casos idênticos ocorra no mesmo dia de apresentação) em uma próxima oportunidade.

Com relação às habilidades adquiridas com a atividade proposta, verificamos que, além do desenvolvimento da capacidade de comunicação oral, relacionada à habilidade de argumentação, diversas outras habilidades foram estimuladas, de acordo com a opinião dos alunos emitida no final de cada um dos dias em que o mini-simpósio ocorreu. Embora a aprendizagem de conceitos não fosse um dos nossos principais objetivos, sua ocorrência foi mencionada pelos alunos. Habilidades de pesquisa e estímulo à criatividade foram aspectos também fortemente ressaltados. Habilidades de comunicação escrita, trabalho em grupo, tomada de decisão e desenvolvimento do senso crítico, aparentemente, foram aspectos também contemplados pela proposta.

Por fim, a partir das apresentações orais dos alunos, constatamos que a natureza dos casos, aparentemente, dificultou ou facilitou a resolução dos mesmos. Fazemos esta afirmação com base nos argumentos fornecidos pelos grupos para sustentar as suas escolhas. Para o Caso Poluição em Rondônia, sobre o qual os estudantes alegaram a ausência de soluções viáveis para o problema, não foram apresentados muitos argumentos que pudessem justificar as conclusões dos grupos. Em contrapartida, os argumentos produzidos pelos grupos responsáveis pela resolução do Caso das Próteses foram bem mais estruturados, fato que pode estar relacionado às diversas alternativas de solução existentes para o caso e ao fácil acesso a diversas informações a respeito do assunto. Assim, estes aspectos devem ser cuidadosamente considerados na elaboração de outros casos.

\section{CONSIDERAÇÕES FINAIS}

Neste trabalho descrevemos algumas características e aplicações do método de Estudo de Caso no ensino superior de ciências, em especial no ensino superior de química. O conhecimento de tais aspectos por parte de professores e alunos de química pode favorecer a difusão do método que, segundo vários trabalhos relatados na literatura, apresenta potencial para fazer face à fragmentação, à linearidade e ao excessivo individualismo que, constantemente, permeiam os currículos dos cursos de graduação em química.

Acreditamos que a descrição detalhada do método e a apresentação de um exemplo de sua aplicação na disciplina Comunicação e Expressão em Linguagem Científica II podem ser úteis para professores interessados em buscar novas alternativas de ensino que promovam, além do aprendizado de química, a interdisciplinaridade e o trabalho em grupo.

\section{AGRADECIMENTOS}

Ao CNPq, à CAPES e à FAPESP (Processo no 05/54035-3) pelo apoio financeiro e aos alunos matriculados na disciplina SQF321 do IQSC - USP no segundo semestre letivo de 2004.

\section{REFERÊNCIAS}

1. Headrick, K. L.; J. Chem. Educ. 2001, 78, 1281.

2. Lowe, J. P.; J. Chem. Educ. 2001, 78, 1185.

3. Cajén, S. G.; Castiñeiras, J. M. D.; Fernandez, E. G. R.; Enseñanza de Las Ciencias 2002, 20, 217.

4. Zucco, C.; Pessine, F. B. T.; Andrade, J. B.; Quim. Nova 1999, 22, 454.

5. Belt, S. T.; Phipps, L. E.; J. Chem. Educ. 1998, $2,16$.

6. Hutchinson, J. S.; J. Chem. Educ. 2000, 4, 3.

7. Belt, S. T.; Evans, E. H.; McCreedy T.; Overton, T. L.; Summerfield, S.; J. Chem. Educ. 2002, 6, 65 .

8. Sá, L. P.; Dissertação de Mestrado, Universidade de São Paulo, Brasil, 2006.

9. Herreid, C. F.; J. Coll. Sci. Teach. 2003, 32, 364.

10. Andrade, M. A. B. S.; Campos, L. M. L.; Atas do V Encontro Nacional de Pesquisa em Educação de Ciências, Bauru, Brasil, 2005

11. Waterman, M. A.; Bioscene - Journal of College Biology Teaching $\mathbf{1 9 9 8}$ 24,3 .

12. Herreid, C. F.; J. Coll. Sci. Teach. 1997, 27, 92.

13. Cornely, K.; J. Coll. Sci. Teach. 1999, 29, 114.

14. Herreid, C. F.; J. Coll. Sci. Teach. 1994, 23, 221.

15. Conant, J. B.; The Growth of the Experimental Sciences: An Experimental in General Education, New Haven: Yale Univ. Press, 1949. 
16. Challen, P. R.; Brazdil, L. C.; Chem. Educator 1996, 1, 1

17. Lantz, J. M.; Walczak, M. M.; Chem. Educator 1997, 1, 1.

18. Bretz, S. L.; Meinwald, J.; J. Coll. Sci. Teach. 2002, 31, 220.

19. Hodges, L. C.; Harvey, L. C.; Chem. Educator 2003, 8, 346.

20. Peaslee, G.; Lantz, J. M.; Walczak, M. M.; J. Coll. Sci. Teach. 1998, $28,21$.

21. Clark, D. C.; J. Coll. Sci. Teach. 1997, 27, 17.

22. Camill, P.; J. Coll. Sci. Teach. 2000, 30, 38.

23. Karukstis, K. K.; J. Coll. Sci. Teach. 2003, 33, 36

24. Herreid, C. F.; J. Coll. Sci. Teach. 1998, 27, 236.

25. Herreid, C. F.; J. Coll. Sci. Teach. 2004, 33, 12

26. Tärnvik, A.; J. Coll. Sci. Teach. 2002, 32, 94.

27. Cliff, W. H.; Curtin, L. N.; J. Coll. Sci. Teach. 2000, 30, 64.

28. Herreid, C. F.; J. Coll. Sci. Teach. 1998, 27, 163.

29. Herreid, C. F.; J. Coll. Sci. Teach. 1999/2000, 29, 156.

30. Santos, G. R.; Dissertação de Mestrado, Universidade de São Paulo, Brasil, 2006.

31. Herreid, C. F.; J. Coll. Sci. Teach. 1994, 23, 349.

32. Gallucci, K.; J. Coll. Sci. Teach. 2004, 33, 32.

33. Santos, G. R.; Sá, L. P.; Queiroz, S. L.; Quim. Nova 2006, 29, 1121.

34. Niece, B. K.; J. Chem. Educ. 2005, 82, 1521

35. Jones, M. A.; J. Chem. Educ. 1997, 74, 537.

36. Lantz, J. M.; Feindt, J. E.; Lewellyn, E. P. B.; Walczak, M. M.; J. Chem. Educ. 1999, 76, 1671.

37. Dewprashad, B.; Kosky, C.; Vaz. G. S.; Martin, C. L.; J. Chem. Educ. 2004, 81,1471 .
38. Cheng, V. K. W.; J. Chem. Educ. 1995, 72, 525.

39. Krow, G. R.; Krow, J. B.; J. Chem. Educ. 1998, 75, 1583.

40. Dunnivant, F. M.; Moore, A.; Alfano, M. J. Brzenk, R.; Buckley, P. T.; Newman, M. E.; J. Chem. Educ. 2000, 77, 1602

41. Al-Khlaifat, A.; AlRifai, R.; Chem. Educator 2002, 7, 384.

42. Belt, S. T.; Leisvik, M. J.; Hyde, A. J.; Overton, T. L.; Chemistry Education Research and Practice 2005, 6, 166.

43. Brink, C. P.; Goodney, D. E.; Hudak, N. J.; Silverstein, T. P.; J. Chem. Educ. 1995, 72, 530

44. Ciliberto, E.; Spoto, G.; Matteini, M.; Puglisi, C.; J. Chem. Educ. 1998, 75,1302 .

45. Walczak, M. M.; Lantz, J. M.; J. Chem. Educ. 2004, 81, 218.

46. Labianca, D. A.; J. Chem. Educ. 1994, 71, 16.

47. Ringan, N. S.; Grayson, L.; J. Chem. Educ. 1994, 71, 856

48. Cornely, K.; J. Chem. Educ. 1998, 75, 475.

49. Bennett, N.; Cornely, K.; J. Chem. Educ. 2001, 78, 759.

50. Nae, H.; Hofstein, A.; J. Chem. Educ. 1985, 62, 198.

51. Doherty, M. P.; J. Chem. Educ. 1994, 71, 860.

52. Duprey, R.; Sell, C. S.; Lowe, N. D.; J. Chem. Educ. 2003, 80, 513

53. Oliveira, J. R. S.; Queiroz, S. L.; Atas do V Encontro Nacional de Pesquisa em Educação em Ciências, Bauru, Brasil, 2005.

54. http://www.cdcc.usp.br/ciencia/index.html, acessada em Abril 2006.

55. Kortland, K.; Science Education 1996, 80, 673.

56. Queiroz, S. L.; Sá, L. P.; Enseñanza de Las Ciencias 2005, extra, 1. 